\title{
Introduction to the special issue on computer vision in road safety and intelligent traffic
}

\author{
Ankit Chaudhary $^{1^{*}}$ (D), Reinhard Klette ${ }^{2}$, J. L. Raheja ${ }^{3}$ and Xia Jin ${ }^{4}$
}

The importance of road safety has brought technologies from different disciplines into vehicles, to make them more intelligent and more secure to drive. Computer vision has helped in many areas for better services and to fasten the process. Road transport and traffic management are such areas where robust visual techniques are highly advantageous, and they are used increasingly to automate dedicated tasks. Computer vision started to be implemented in on-road vehicles and shows capabilities in the context of road safety such that transportation becomes safer, comfortable, and easy. Vision can help in smoothening traffic, predicting collisions and blind spots on roads. Also, it can help in a driverless mode in the car driving in case of emergency. Some companies have already launched cars which are having vision-based capabilities that are helpful in making a decision on the road. Researchers use vision-based processing in traffic management and traffic surveillance. There are very good prospects that this development will intensify and widen in the near future.

This special issue covers a range of topics in road safety that have captured high attention and interest of the research community in recent years. The topics include efficient vehicle detection to driver awareness checking. This special issue concerns computer vision subjects in automated solutions for road safety, but also for the cases where the human factor involved in transportation and safety systems plays a significant role. This issue is an effective source for researchers to see latest results and findings on traffic-related issues, new ideas, and directions for future development.

The first paper [1] presents a novel method to detect driver's aggressiveness on road based on visual and sensor information. Visual information was used to detect road lines and vehicle images, while sensors were

\footnotetext{
* Correspondence: dr.ankit@ieee.org

'Department of Computer Science, Northwest Missouri State University, Maryville, USA

Full list of author information is available at the end of the article
}

used for measuring engine and vehicle speed. Data were modeled using Gaussian distributions, and 93.1\% accuracy on real traffic was measured.

The second paper [2] deals with driver's head pose estimation which is the part of driver assistance system to know driver's attention. An appearance-based discrete head pose estimation was done using monocular visible spectrum images. A fusion of four different techniques was used to get face descriptor, and SVM was used for classification.

While the first and second papers focus on information about the driver, the third paper [3] shows better results for on-road vehicle detection. The proposed system selects few weak classifiers that are expected to show good performance in real environments. At cascading, weak classifiers using AdaBoost were tested for biasing and discarded after observing results. The selection process restarts again after weight adjustment.

The fourth paper [4] proposes an on-road vehicle detection method based on visual odometry. The 2D scene and motion constraints were applied at the lowest level. The uncertainty associated with the inverse perspective projection and a parameter space voting scheme were used to find vehicle state among tracked features. This study shows that this method performed better than the basic 3D pose estimation due to exploitation on the largely planar structure.

In conclusion, we consider the outcome of this special issue brings state-of-the-art papers together in the field of road safety and would be a source of information for researchers in the coming years. At the same time, it seems many questions are still unanswered. We hope these papers can stimulate further and yet deeper research in this exciting field.

We would like to express our deep thanks to the Editor-in-Chief, Dr. Jean-Luc Dugelay, for providing us the opportunity to handle this special issue and his Springer JIVP editorial staff for their support and help. We also thank all the authors who submitted their 
papers, as well the thoughtful work of the many reviewers who have provided invaluable evaluations and recommendations in a timely manner. Finally, I thank all my guest editors for their great support who helped me in organizing this issue.

\section{Competing interests}

The authors declare that they have no competing interests.

\section{Author details}

'Department of Computer Science, Northwest Missouri State University, Maryville, USA. ${ }^{2}$ Department of Computer Science, The University of Auckland, Auckland, New Zealand. ${ }^{3}$ Machine Vision Lab, CEERI, Pilani, India. ${ }^{4}$ Department of Civil \& Environmental Engg, Florida International University, Miami, USA.

Received: 20 January 2017 Accepted: 30 January 2017

Published online: 14 February 2017

\section{References}

1. O Kumtepe, GB Akar, E Yuncu, Driver aggressiveness detection via multisensory data fusion. EURASIP J Image Video Process 2016(5), 1-16 (2016). doi:10.1186/s13640-016-0106-9

2. N Alioua, A Amine, A Rogozan, A Bensrhair, M Rziza, Driver head pose estimation using efficient descriptor fusion. EURASIP J Image Video Process 2016(2), 1-14 (2016). doi:10.1186/s13640-016-0103-z

3. H Cho, S Hwang, High-performance on-road vehicle detection with non-biased cascade classifier by weight-balanced training. EURASIP I Image Video Process 2015(16), 1-7 (2015). doi:10.1186/s13640-015-0074-5a

4. DV Hamme, W Goeman, P Veelaert, W Philips, Robust monocular visual odometry for road vehicles using uncertain perspective projection. EURASIP $\mathrm{J}$ Image Video Process 2015(10), 1-21 (2015). doi:10.1186/s13640-015-0065-6

\section{Submit your manuscript to a SpringerOpen ${ }^{\circ}$ journal and benefit from:}

- Convenient online submission

- Rigorous peer review

- Immediate publication on acceptance

- Open access: articles freely available online

- High visibility within the field

- Retaining the copyright to your article 